\title{
Über Proteolyse in der Thymus des Kalbes. \\ Von
}

Nils J. Rhodin.

(Aus dem medizinisch-chemischen Institute in Upsala.)

(Der Redaktion zugegangen am 21. August 1911.)

Proteolytische Wirkungen in der Thymus sind früher von Kutscher ${ }^{1}$ ) und Jones ${ }^{2}$ ) beobachtet worden, welche nach längerer Autolyse die Spaltungsprodukte analysierten. Hedin ${ }^{3}$ ) fand, daß die Thymus in saurer Flüssigkeit eine weitaus stärkere Autolyse erfährt als in alkalischer. Bei Versuchen mit anderen Organen vom Rind hat sich dieses Verhältnis als vorherrschend erwiesen (Biondi ${ }^{4}$ ) an der Leber, Hedin u. Rowland ${ }^{5}$ ) an der Milz u. a. Organen). Ferner hat es sich gezeigt, daß mit Säure vorbehandelte Organe mit Alkali eine kräftigere Proteolyse bewirken als mit Alkali vorbehandelte (Hedin). ${ }^{5}$ ) Dies gilt auch für Milz, Thymus, Leber, Nieren, Testis, Muskeln und wahrscheinlich für alle Organe. Was die Milz anbelangt, so beruht dies auf dem Vorhandensein einer Substanz, welche in alkalischer Flüssigkeit die Proteolyse hemmt und die bei der Behandlung mit Säure zerstört wird. Auch das Blutserum des Rindes enthält eine solche hemmende Substanz, welche bei der Behandlung mit Säure ebenfalls ihre Wirkung einbüßt, und es ist möglich, daß die im Blute und die in der Milz vorkommenden Substanzen identisch sind, was indessen nicht bewiesen ist.

1) Diese Zeitschrift, Bd.34, S. 114-118.

2) Americ. Journal of Physiology Bd.10, S. XXIV-XXV.

3) Festschrift für Olof Hammarsten, VI, S. 4 u. 5.

4) Virchows Archiv, Bd. 144, S. 373, 1896.

$\left.{ }^{5}\right)$ Festschrift für Olof Hammarsten, VI. 
Proteolyse in saurer, mit $\mathrm{CaCO}_{3}$ versetzter und alkalischer Flüssigkeit.

A. $5 \mathrm{~g}$ gemahlene Thymus wurden teils mit $20 \mathrm{ccm}$ Wasser und etwas Calciumcarbonat teils mit $20 \mathrm{ccm}$ 0,2\% \% iger Essigsäure versetzt; beide Proben machten dann Autolyse von 24 Stunden durch. Toluol und Chloroform wurden als Antiseptica angewendet. Die Größe der Digestion wurde durch Ausfällen mit

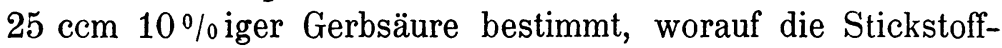
bestimmung an $25 \mathrm{ccm}$ des Filtrates (nach Kjeldahls Methode) gemacht wurde. Untenstehende Zahlen geben die Anzahl ccm 1/10-n-Schwefelsäure an, welche für die Bindung des gebildeten Ammoniaks gebraucht wurden.

\begin{tabular}{l|c|c}
\hline & $\begin{array}{c}\text { Digestion in mit } \mathrm{CaCO}_{3} \\
\text { versetzter Flüssigkeit }\end{array}$ & $\begin{array}{c}\text { Digestion } \\
\text { in saurer Flüssigkeit }\end{array}$ \\
\hline Versuch I & 11,5 & 44,5 \\
Versuch II & 9,8 & 57,6 \\
Versuch III & 9,3 & $4 \check{5}, 2$
\end{tabular}

B. Der Versuch wurde mit säureextrahiertem Enzym (auf weiter unten beschriebene Weise zubereitet) wiederholt. Als Substrat wurde in einem Falle $200 \mathrm{ccm}$ alkalische $\left(0,25 \% \mathrm{Na}_{2} \mathrm{CO}_{3}\right)$ 2,5\% ige Caseinlösung angewandt. Im anderen Falle war das

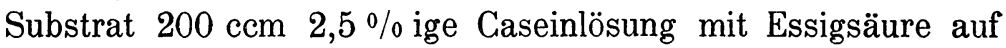
$0,1 \%$ versetzt. In beiden Versuchen wurde $10 \mathrm{ccm}$ Enzymlösung genommen. Bei der Analyse wurde mit $100 \mathrm{ccm} 10 \%$ iger Gerbsäure ausgefällt und mit $100 \mathrm{ccm}$ des Filtrates die Stickstoffbestimmung gemacht. Die Digestion dauerte 24 Stunden bei $37^{\circ} \mathrm{C}$.

\begin{tabular}{c|c|c}
\hline \hline & $\begin{array}{c}\text { In alkalischer Casein- } \\
\text { lösung }\end{array}$ & In saurer Caseinlösung \\
\hline & 38,3 & 62
\end{tabular}

Aus den Resultaten der Versuche A und B geht hervor, daß die Proteolyse in saurer Flüssigkeit bedeutend stärker ist, als in neutraler oder alkalischer - in voller Übereinstimmung mit früheren Beobachtungen an der Thymus und anderen Organen. 
Vorbehandlung in saurer und neutraler Flüssigkeit und darauf folgende Proteolyse mit Casein in alkalischer Lösung.

$15 \mathrm{~g}$ gemahlene Thymus wurden 24 Stunden teils mit $30 \mathrm{ccm} 0,2 \%$ iger Essigsäure teils mit $30 \mathrm{ccm}$ Wasser, versetzt mit etwas $\mathrm{CaCO}_{3}$, behandelt. Darauf wurde die mit Essigsäure behandelte Probe mit $\mathrm{CaCO}_{3}$ neutralisiert, und zu beiden $100 \mathrm{ccm}$ alkalische $\left(0,25 \% \mathrm{Na}_{2} \mathrm{CO}_{3}\right) \quad 2,5 \%$ ige Caseinlösung zugesetzt, wonach 24 Stunden digeriert wurde. $50 \mathrm{ccm}$ Gerbsäure wurden zum Ausfällen angewendet und zur Analyse wurden $100 \mathrm{ccm}$ des Filtrates benutzt. Die Ziffern unten geben die Anzahl ccm 1/10-n-Schwefelsäure an, welche, um das gebildete Ammoniak zu binden, gebraucht werden, nachdem die Ammoniakmenge abgezogen worden war, die der während der Vorbehandlung stattgefundenen Proteolyse entsprach.

\begin{tabular}{c|c|c}
\hline & $\begin{array}{c}\text { Nach Vorbehandlung } \\
\text { mit } \mathrm{CaCO}_{3}\end{array}$ & $\begin{array}{c}\text { Nach Vorbehandlung } \\
\text { mit Essigsäure }\end{array}$ \\
\hline 35,5 & 71,2
\end{tabular}

Das Resultat zeigt eine bedeutend stärkere Enzymwirkung nach der Vorbehandlung mit Säure als mit $\mathrm{CaCO}_{3}$, analog mit früheren Beobachtungen an anderen Organen.

Im folgenden Versuche wurde Proteolyse einerseits sofort (ohne Vorbehandlung), anderseits nach Vorbehandlung mit $\mathrm{CaCO}_{3}$ bezw. Essigsäure vorgenommen.

$5 \mathrm{~g}$ gemahlene Thymus wurden mit $200 \mathrm{ccm}$ alkalischer Caseinlösung versetzt und 24 Stunden bei $37^{\circ} \mathrm{C}$. gehalten.

$5 \mathrm{~g}$ wurden in einem Falle mit $10 \mathrm{ccm}$ mit $\mathrm{CaCO}_{3}$ verversetztem Wasser, im anderen Falle mit $10 \mathrm{~cm} 0,2 \%$ iger Essigsäure bei $37^{\circ}$ C. vorbehandelt. Nachdem die letztere Probe mit $\mathrm{CaCO}_{3}$ neutralisiert worden, wurde zu beiden $200 \mathrm{ccm}$ alkalische Caseinlösung zugesetzt und 24 Stunden digeriert. Zur Analyse wurden $100 \mathrm{~cm} \mathrm{10 \%} \mathrm{ige} \mathrm{Gerbsäure} \mathrm{angewendet} \mathrm{(ebenso}$ bei allen folgenden Versuchen, wo $200 \mathrm{ccm}$ Caseinlösung verwendet wurde). Bei allen drei Digestionsversuchen wurde genau darauf geachtet, daß vor dem Ausfällen mit Gerbsäure das Volu- 
men der sämtlichen Proben das gleiche war. Von den erhaltenen Zahlen wurde für den während der Vorbehandlung gebildeten Stickstoff ein Abzug gemacht.

\begin{tabular}{l|c|c|c}
\hline \hline & $\begin{array}{c}\text { Ohne } \\
\text { Vorbehandlung }\end{array}$ & $\begin{array}{c}\text { Nach } \mathrm{CaCO}_{3}- \\
\text { Vorbehandlung }\end{array}$ & $\begin{array}{c}\text { Nach Essigsäure- } \\
\text { Vorbehandlung }\end{array}$ \\
\hline Versuch I & 46,3 & 44,8 & 50,7 \\
Versuch Il & 57,7 & 47,8 & 59,4
\end{tabular}

Aus dem Vergleich zwischen der gleich (ohne Vorbehandlung) vorgenommenen Proteolyse und der nach Vorbehandlung mit $\mathrm{CaCO}_{3}$ bezw. Essigsäure scheint hervorzugehen, daß $\mathrm{CaCO}_{3}$ die Enzymwirkung etwas abschwächt, während die Essigsäure dieselbe begünstigt.

Vorbehandlung in saurer und alkalischer Lösung, darauffolgende

Proteolyse mit Casein bei alkalischer Reaktion.

Dieselben Versuche wurden daraufhin so wiederholt, daß das $\mathrm{CaCO}_{3}$-Wasser durch $0,1 \%$ ige $\mathrm{Na}_{2} \mathrm{CO}_{3}$-Lösung ersetzt wurde.

\begin{tabular}{c|c|c|c}
\hline \hline & $\begin{array}{c}\text { Ohne } \\
\text { Vorbehandlung }\end{array}$ & $\begin{array}{c}\text { Nach Vorbehandlung } \\
\text { mit } 0,1 \% \quad \mathrm{Na}_{8} \mathrm{CO}_{8}\end{array}$ & $\begin{array}{l}\text { Nach Vorbehandlung } \\
\text { mit 0,2\% Essigsäure }\end{array}$ \\
\hline & 32,2 & 24,7 & 49,6
\end{tabular}

Vergleicht man die Größe der Proteolyse, gleich vorgenommen und nach Alkalibehandlung, so zeigt sich, daß das Alkali bedeutend mehr als das $\mathrm{CaCO}_{3}$ hemmt. Aber die Differenz zwischen der Digestion gleich und nach Alkalibehandlung ist nicht so groß, wie man nach analogen Versuchen Hedins ${ }^{1}$ ) mit der Milz erwarten könnte.

Säure- bezw. Alkalibehandlung von säureextrahierter Enzymlösung und darauffolgende Digestion mit Casein in alkalischer Flüssigkeit.

Das Enzymextrakt des Organes wurde auf die Weise dargestellt, daß ein Teil gemahlene Thymus mit zwei Teilen saures Wasser $(0,2 \%$ Essigsäure) versetzt wurde. Das Gemisch wurde einer 24 stündigen Autolyse bei $37^{\circ} \mathrm{C}$. unterworfen. Darauf

1) Festschrift für Olof Hammarsten, VI, S. 7. 
wurde filtriert und neutralisiert, und das Filtrat zur Entfernung der Spaltungsprodukte dialysiert.

Die vorhergehenden Versuche wurden dann wiederholt. $5 \mathbf{g}$ gemahlene Thymus wurden mit $10 \mathrm{ccm}$ Enzymlösung versetzt.

\begin{tabular}{c|c|c|c}
\hline \hline & $\begin{array}{c}\text { Ohne } \\
\text { Vorbehandlung }\end{array}$ & $\begin{array}{c}\text { Nach Vorbehandlung } \\
\text { mit } 0,1 \% \text { Alkali }\end{array}$ & $\begin{array}{c}\text { Nach Vorbehandlung } \\
\text { mit } 0,2 \% \text { Säure }\end{array}$ \\
\hline & 48,5 & 35,9 & 53,4
\end{tabular}

Aus unten angeführten Gründen (siehe Zusammenfassung 2) ist die hemmende Wirkung des Alkalis in diesen wie in den vorhergegangenen Versuchen möglicherweise so zu erklären, daß Enzym bei der Vorbehandlung mit Alkali zum Teil zerstört wurde.

Versuche mit Enzymlösungen bereitet bei saurer bezw. neutraler Reaktion.

Enzym wurde einerseits wie vorher mit Säure bereitet (ein Teil Thymus + zwei Teile 0,2\% ige Essigsäure). Anderseits wurde eine neutrale Infusion so bereitet, daß zu einem Teile gemahlene Drüse zwei Teile mit $\mathrm{CaCO}_{3}$ versetztes Wasser zugesetzt wurden, worauf das Gemisch 24 Stunden bei $37^{\circ}$ gehalten wurde. Dann wurde ebenso wie bei der Bereitung von saurer Infusion filtriert und dialysiert.

Die Digestionsversuche wurden so angestellt, daß $10 \mathrm{ccm}$ Enzymlösung 24 Stunden bei $37^{\circ}$ C. mit $100 \mathrm{ccm}$ alkalischer Caseinlösung hingestellt wurde.

\begin{tabular}{l|c|c}
\hline & Saure Infusion & Neutrale Infusion \\
\hline Versuch I & 27,6 & 22,1 \\
Versuch II (neue & 28,2 & 23,9 \\
Enzymbereitung) & &
\end{tabular}

Der Versuch zeigt, daß durch Extraktion mit Säure eine stärker wirkende Enzymlösung als mit $\mathrm{CaCO}_{3}$ erhalten wird, was ja nach den vorhergegangenen Versuchen, wo die Vorbehandlung mit Säure die Enzymlösung verstärkt und $\mathrm{CaCO}_{3}$ dieselbe abschwächt, zu erwarten war.

Hoppe-Seyler's Zeitschrift f. physiol. Chemie. LXXV. 


\section{Hemmungsversuche mit Serum und Serumalbumin an säureextrahiertem Enzym.}

Folgende Versuche zeigen, wie sich das Serum als Hemmungskörper bei der Proteolyse verhält. $\mathrm{Zu}$ jedem Versuche sind $10 \mathrm{ccm}$ Enzymlösung, $10 \mathrm{ccm}$ Serum bezw. Serumalbumin und $100 \mathrm{~cm}$ alkalische $2,5 \%$ ige Caseinlösung $(50 \mathrm{~cm} 10 \%$ ige Gerbsäure) verwendet worden. In den Versuchen ohne Serum wurde anstatt dessen das gleiche Volumen Wasser zugesetzt. Das Serum war neutralisiertes Ochsenserum. Das Serumalbumin wurde in der Weise dargestellt, daß die Globuline aus dem Ochsenserum durch halbe Sättigung mit $\mathrm{Am}_{2} \mathrm{SO}_{4}$ entfernt wurden, worauf das Serumalbumin durch völlige Sättigung mit demselben Salze ausgefällt und das Salz wegdialysiert wurde. Um festzustellen, ob die Reihenfolge, in welcher die reagierenden Substanzen - Enzym, Hemmungskörper, Substrat - mit einander vermischt wurden, irgend welche Rolle spielt, ist in einem Teile der Versuche Serum bezw. Serumalbumin vor dem Zugeben des Caseins dem Enzym zugesetzt und bei $37^{\circ} \mathrm{C}$. eine Stunde gehalten worden.

\begin{tabular}{|c|c|c|c|}
\hline & Ohne Serum & $\begin{array}{l}\text { Serum eine } \\
\text { Stunde vor Beginn } \\
\text { der Digestion dem } \\
\text { Enzym zugesetzt }\end{array}$ & $\begin{array}{l}\text { Serum gleichzeitig } \\
\text { mit Enzymlösung } \\
\text { dem Caseinzugesetzt }\end{array}$ \\
\hline Versuch I & 26,2 & 20,9 & 20,9 \\
\hline Versuch II & 21 & 16,8 & 17,7 \\
\hline
\end{tabular}

\begin{tabular}{l|c|c|c}
\hline \hline & Ohne Serumalbumin & $\begin{array}{c}\text { Serumalbumin eine } \\
\text { Stunde vor Beginn } \\
\text { der Digestion dem } \\
\text { Enzym zugesetzt }\end{array}$ & $\begin{array}{c}\text { Serumalbumin } \\
\text { gleichzeitig mit } \\
\text { Enzymlösung dem } \\
\text { Casein zugesetzt }\end{array}$ \\
\hline Versuch I & 26,9 & 15,6 & 17,2 \\
Versuch II & 27,1 & 22,1 & 22,3 \\
Versuch III & 21,3 & 17,5 & 18,1
\end{tabular}

Die Versuche zeigen, daß im Serum ein Körper vorhanden ist, welcher die Proteolyse hemmt, und daß dieser vom Serum 
zusammen mit dem Serumalbumin geschieden werden kann. Die Reihenfolge des Zusetzens von Serum bezw. Serumalbumin ist offenbar ohne Bedeutung.

\section{Behandlung des Hemmungskörpers mit Säure.}

Der Hemmungskörper wird, wie aus folgenden Versuchen hervorgeht, durch Behandlung mit 0,2\% iger Essigsäure während 24 Stunden nicht zerstört.

\begin{tabular}{l|c|c|c}
\hline & Ohne Serum & $\begin{array}{c}\text { Mit } \\
\text { Säure behandeltes } \\
\text { Serumalbumin }\end{array}$ & $\begin{array}{c}\text { Mit Säure + Alkali } \\
\text { behandeltes } \\
\text { Serumalbumin }\end{array}$ \\
\hline Versuch I & 25,1 & 21,7 & 19,9 \\
Versuch II & 27,6 & 20,4 & 21,1
\end{tabular}

Das Verhalten, daß sowohl natives als auch mit $0,2 \%$ iger Essigsäure denaturiertes Serumalbumin die Proteolyse hemmt, und daß die Reihenfolge des Mischens ohne Belang ist, deutet darauf hin, daß keinerlei irreversible Verbindung zwischen dem Enzym und dem Hemmungskörper gebildet wird, sondern nur eine reversible. Es würde also eine "Ablenkung» des Enzymes im Sinne Hedins sein. ${ }^{1}$ )

Hemmungsversuche mit Serum bezw. Serumalbumin auf Enzym, welches in neutraler Flüssigkeit extrahiert worden war.

Die Versuche wurden auf die gleiche Weise wie die mit säureextrahiertem Enzym angestellt.

\begin{tabular}{l|c|c|c}
\hline \hline & Ohne Serum & $\begin{array}{c}\text { Serum eine Stunde } \\
\text { vor dem Substrate } \\
\text { dem Enzym zu- } \\
\text { gesetzt }\end{array}$ & $\begin{array}{c}\text { Serum gleichzeitig } \\
\text { mit Enzymlösung } \\
\text { dem Substrate zu- } \\
\text { gesetzt }\end{array}$ \\
\hline Versuch I & 29,6 & 32,8 & 30,7 \\
Versuch II & 30,2 & 32,1 & 31,4
\end{tabular}

1) Hedin, Über verschiedenartige Hemmung der tryptischen Verdauung. Diese Zeitschrift, Bd. 52, S. 412. 


\begin{tabular}{l|c|c|c}
\hline \hline & Ohne Serumalbumin & $\begin{array}{c}\text { Serumalbumin eine } \\
\text { Stunde vor dem } \\
\text { Substrate dem } \\
\text { Enzym zugesetzt }\end{array}$ & $\begin{array}{c}\text { Serumalbumin } \\
\text { gleichzeitig mit } \\
\text { Enzymlösung dem } \\
\text { Substrate zugesetzt }\end{array}$ \\
\hline Versuch I & 24,3 & 25,1 & 24,7 \\
Versuch II & 28,9 & 30,7 & 30,2
\end{tabular}

Der Versuch zeigt, daß die Enzymlösung, welche durch Extraktion in neutraler Flüssigkeit gewonnen wird, nicht die Eigenschaft besitzt, durch Serum bezw. Serumalbumin in seiner Wirkung gehemmt zu werden. Die Ziffern deuten eher auf eine Begünstigung der Enzymwirkung hin unter dem Einfluß von Serum bezw. Serumalbumin. Die Reihenfolge des Zusatzes ist auch hier bedeutungslos.

\section{Kaolinbehandlung der Enzymlösungen.}

Versuche sind dann darüber angestellt worden, die Enzymlösungen so weit als möglich von Eiweiß zu befreien. Ich habe mir dabei die Fähigkeit des Kaolins, Eiweiß den Lösungen $z u$ entziehen, zunutze gemacht. Mit einer Sorte Kaolin (unbekannten Ursprungs) gelang es mir, praktisch genommen, eine durch neutrale Infusion bereitete Enzymlösung von Eiweiß zu befreien. $\mathrm{Zu} 100 \mathrm{ccm}$ Enzymlösung wurden $60 \mathrm{~g}$ Kaolin gesetzt und das Ganze genau umgeschüttelt. Das Kaolin wurde nach 2-3 Stunden durch Zentrifugieren und Filtrieren ausgeschieden. Das Filtrat, welches vollkommen klar und farblos war, gab mit 10\% iger Gerbsäure keine sofortige Fällung, aber nach 24 Stunden entstand eine schwache Opalescenz. Digestionsversuche wurden sogleich gemacht.

\begin{tabular}{c|c|c}
\hline \hline Neutral bereitetes Enzym & $\begin{array}{c}\text { Kaolinbehandeltes neutral } \\
\text { bereitetes Enzym }\end{array}$ \\
\hline & 10,4 & 8,7
\end{tabular}

Da dieses Kaolin bald zu Ende war und ich kein gleichartiges beschaffen konnte, mißlang mir der Versuch verschie- 
dene Male mit anderen Kaolinsorten. Schließlich erhielt ich ein Kaolin (Kahlbaum, Berlin), welches gleich wie das erstgenannte im Verhältnis 60 Kaolin zu 100 Enzymlösung mit größter Leichtigkeit das Eiweiß aus der Lösung abtrennte. Doch ging dies bei mit Säure hergestelltem Enzym leichter als bei mit $\mathrm{CaCO}_{3}$ bereitetem, was zu erwarten war, da bei der neutralen oder schwach alkalischen Infusion mehr Eiweiß in Lösung geht als bei der sauren.

\begin{tabular}{c|c|c}
\hline & Säurebereitetes Enzym & $\begin{array}{c}\text { Säurebereitetes, kaolin- } \\
\text { behandeltes Enzym }\end{array}$ \\
\hline & 12,2 & 8,8
\end{tabular}

Aus den Digestionsversuchen geht hervor, daß das Kaelin gleichzeitig mit dem Eiweiß nur einen Teil des Enzymes mit adsorbiert.

\section{Zusammenfassung.}

Aus meinen Versuchen geht folgendes hervor:

I. Direkte Proteolyse in saurer Flüssigkeit ist bedeutend stärker als in alkalischer und neutraler in voller Übereinstimmung mit früheren Beobachtungen. Dasselbe gilt auch für aus Infusion des Organs dargestellte Enzymlösungen.

II. Nach Vorbehandlung mit Alkalien oder $\mathrm{CaCO}_{3}$ wird eine schwächere Proteolyse in alkalischer Lösung erhalten als nach Vorbehandlung mit Säure. Ob das auf Zerstörung von Enzym bei der Vorbehandlung mit Alkalien oder $\mathrm{CaCO}_{3}$ beruht oder ob es wie bei Versuchen mit Milz (Hedin) dadurch erklärt werden kann, daß eine hemmende Substanz bei der Vorbehandlung mit Säure zerstört wird, muß dahingestellt bleiben. Irgend welche hemmende Substanz ist nicht in der Thymusdrüse nachgewiesen worden, und in diesem Falle enthält das Blut auch keine durch Säure zerlegbare hemmende Substanz, wie es bei der Milz der Fall war. Überhaupt scheinen die proteolytischen Enzyme in der Milz und die in der Thymus von verschiedener Art $\mathrm{zu}$ sein - was bereits 
206 Nils J. Rhodin, Über Proteolyse in der Thymus des Kalbes.

auf Grund der Verschiedenartigkeit zwischen deren gewebebildenden Elementen zu erwarten war.

III. Durch Infusion des Organes mit 0,2\% iger Essigsäure dargestelltes Enzym wird durch Ochsenserum schwach gehemmt (Ablenkung). Durch neutrale Infusion $\left(\mathrm{CaCO}_{3}\right)$ erhaltenes Enzym wird nicht gehemmt.

IV. Kaolin in Mengen, die das Eiweiß vollständig niederreißen, nimmt neutral bezw. säurebereitetes Enzym entweder nicht oder nur zum Teile auf. 